\title{
ENSINO DA AIDS NA PERSPECTIVA DE DOCENTES DE ENFERMAGEM E SUA RELAÇÃO COM A COMPLEXIDADE*
}

\author{
Simone de Oliveira Camilloº, Fabiana Tavolaro Maiorino² ${ }^{2}$ Ana Lúcia da Silva ${ }^{3}$
}

'Enfermeira. Doutora em Ciências. Faculdade de Medicina da Fundação do ABC. Santo André-SP-Brasil.

${ }^{2}$ Psicóloga. Mestre em Comunicação e Semiótica. Universidade Paulista de São Paulo. São Paulo-SP-Brasil.

${ }^{3}$ Enfermeira. Doutora em Enfermagem. Secretaria de Estado da Saúde de São Paulo. São Paulo-SP-Brasil.

RESUMO: Estudo cujo objetivo foi investigar a percepção dos docentes de Enfermagem sobre a sua prática pedagógica em HIV/Aids, tendo como referencial teórico o Pensamento Complexo. Trata-se de pesquisa qualitativa com treze docentes graduados em Enfermagem, entre janeiro e julho de 2010, pertencentes a sete Instituições de Ensino Superior de São Paulo. O estudo obedeceu aos princípios éticos e a coleta de dados se deu por meio da Entrevista em Profundidade. Os resultados foram trabalhados pela análise de conteúdo. As categorias evidenciaram que o processo de ensino em HIV/Aids, com base no modelo biomédico, não restringiu o ensino da ética e da cidadania, do estímulo à curiosidade e da criatividade, muito menos, da compreensão do humano com HIV/Aids como um ser complexo, por parte dos docentes. Este estudo mostra a importância da valorização do ensino em relação ao tema HIV/Aids pautado na condição e na solidariedade humana. DESCRITORES: Educação em enfermagem; Filosofia em enfermagem; Educação superior; Conhecimento; Síndrome de imunodeficiência adquirida.

\section{THE TEACHING OF AIDS IN THE VIEW OF LECTURERS OF NURSING AND ITS RELATIONSHIP WITH COMPLEXITY}

\begin{abstract}
This study aimed to investigate nursing lecturers' perception regarding their pedagogical practice regarding HIV/AIDS, using Complex Thought as the theoretical framework. This is qualitative research with 13 lecturers who graduated in Nursing, belonging to seven Higher Education Institutions in São Paulo, and was undertaken between January and July 2010. The study respected ethical principles and the data collection occurred through In-depth Interviews. The results were treated using content analysis. The categories evidenced that the teaching process in HIV/AIDS, based in the biomedical model, did not restrict the teaching of ethics, citizenship, encouragement for curiosity, and creativity, much less the understanding of the person with HIV/AIDS as a complex being, on the part of the lecturers. This study shows the importance of valuing teaching in relation to the issue of HIV/AIDS grounded in the human condition and in human solidarity.
\end{abstract}

DESCRIPTORS: Education in nursing; Philosophy in nursing; Higher education; Knowledge; Acquired immunodeficiency syndrome

\section{ENSEÑANZA DE SIDA EN LA PERSPECTIVA DE DOCENTES DE ENFERMERÍA Y SU RELACIÓN CON LA COMPLEJIDAD}

RESUMEN: Estudio cuyo objetivo fue investigar la percepción de los docentes de Enfermería sobre su práctica pedagógica en HIV/Sida, utilizando como referencial teórico el Pensamiento Complejo. Es una investigación cualitativa, realizada entre enero y julio de 2010, con trece docentes graduados en Enfermería de siete Instituciones de Enseñanza Superior de São Paulo. El estudio obedeció a los principios éticos y los datos fueron obtenidos por medio de la Entrevista en Profundidad. Los resultados fueron trabajados por el análisis de contenido. Las categorías evidenciaron que el proceso de enseñanza en HIV/Sida, con base en el modelo biomédico, no restringió la enseñanza de la ética y de la ciudadanía, del estímulo a la curiosidad y de la creatividad, mucho menos, de la comprensión del humano con HIV/Sida como un ser complejo, por parte de los docentes. Este estudio muestra la importancia de la valoración de la enseñanza acerca del tema HIV/Sida pautado en la condición y en la solidaridad humana. DESCRIPTORES: Educación en enfermería; Filosofía en enfermería; Educación superior; Conocimiento; Síndrome de inmunodeficiencia adquirida.

*Artigo extraído da tese Compreensão do ensino da Síndrome de Imunodeficiência Adquirida na perspectiva dos docentes de graduação em enfermagem sob o olhar do Pensamento Complexo. Institutos de Pesquisa da Secretaria de Estado de Saúde, 2012. 


\section{INTRODUÇÃO}

A epidemia da Síndrome da Imunodeficiência Adquirida (aids) causada pelo vírus da imunodeficiência humana (HIV) provocou transformações locais e mundiais em aspectos cruciais da vida humana, como a relação de cada um com seu próprio corpo e com outras pessoas, no âmbito privado e até em questões sociais, culturais, econômicas e políticas. Forçou a sociedade a debater temas como gênero, homossexualidade, drogas e a refletir sobre direitos humanos e cidadania ${ }^{(1)}$.

Da mesma forma, o campo de trabalho na área da saúde em relação à temática da aids tornou-se lugar privilegiado para questionamentos em relação ao sistema de saúde vigente, e certamente, essas respostas contribuíram de maneira singular para confrontar diretrizes autoritárias e preconceituosas. O fenômeno da Aids recorda à humanidade a necessidade do enfrentamento de questões que estavam sendo tratadas com descaso ou ignoradas ${ }^{(1)}$.

Os aspectos sociais, políticos, históricos e antropológicos em relação à temática da aids formam parte significativa suscitada pela imensa rede de significações e implicações humanas que a epidemia teceu nas últimas décadas, provocando discussões que dizem respeito não só à política de saúde, mas também, à ética, à moralidade, à novas possibilidades de exercício de cidadania. Portanto, aportes científicos advindos das ciências humanas são fundamentais( ${ }^{(2)}$. Diante disso, o diálogo acerca dos problemas que se construíram em torno da vivência da epidemia, impôs a interlocução com diferentes saberes, colocando em evidência a articulação das esferas biopsicossocial na dimensão humana ${ }^{(3)}$.

Em decorrência, novos desafios são colocados às áreas do conhecimento, entre as quais, a Enfermagem. Entretanto, sabemos que a Enfermagem brasileira se constituiu dentro do modelo biomédico, ou seja, o ensino e consequentemente, o desenvolvimento do seu trabalho, quase sempre foi centrado na concepção biologicista, com atuação individualista e curativa no campo hospitalar. Desta forma, deixa de considerar a influência de fatores psicoemocionais e sócio-ambientais no processo saúde-doença, compreendendo o corpo humano como objeto que pode ser desmontado e seus mistérios entendidos de forma racional. Em virtude disso, enfermeiros apresentam um cuidado muito mais centrado na dimensão das necessidades físicas dos enfermos ${ }^{(4)}$.

Entretanto, é oportuno mencionar que não se trata de desvalorizar os aspectos biológicos quando pensamos na concepção de saúdedoença dentro do ensino em enfermagem. Sabemos que os aspectos biológicos são fundamentais no processo saúde-doença. Porém, é necessário considerarmos também os aspectos psicossociais tão importantes quanto o aspecto biológico.

Portanto, cabe o questionamento: como os docentes de Enfermagem percebem sua prática pedagógica em HIV/aids? Será que o docente de enfermagem, diante de sua formação tecnicista e biologicista, valoriza a construção do conhecimento em relação ao cuidado que envolva dimensões psicossociais no processo ensino-aprendizagem em aids?

Nesse sentido, partimos do pressuposto que diante da exploração da temática da aids, o papel de intermediar a construção do conhecimento do docente é extremamente importante. Ele tem a responsabilidade de participar da construção do conhecimento contextualizado em relação às dimensões da Aids que dizem respeito não só aos aspectos biológicos da doença, mas também, das políticas de saúde, da ética, da moralidade e das novas possibilidades de exercício de cidadania. Assim, problemas de saúde em relação a Aids não devem ser somente avaliados e tratados sob a dimensão biológica.

Portanto, o objetivo proposto para este estudo foi investigar a percepção dos docentes de Enfermagem sobre a sua prática pedagógica em HIV/Aids.

\section{MÉTODO}

Trata-se de estudo qualitativo pautado no referencial teórico-metodológico do Pensamento Complexo, estudado e defendido por Edgar Morin ${ }^{(5)}$, que surge para questionar a fragmentação e o esfacelamento do conhecimento oriundo do século XVI.

A partir deste fundamento, o Pensamento Complexo é definido como um sistema de pensamento aberto, abrangente e flexível 
que não reduz a multidimensionalidade às explicações simplistas ou esquemas fechados de ideias. Configura uma nova visão de mundo que aceita e procura compreender mudanças constantes do real. Não nega a multiplicidade, a aleatoriedade e a incerteza. Baseia-se em sete princípios: hologramático, dialógico, do circuito recursivo, sistêmico ou organizacional, do circuito retroativo, da autonomia/dependência (auto-organização) e o princípio da reintrodução do conhecimento em todo conhecimento. Para esta pesquisa, elegemos os princípios: dialógico, recursivo e hologramático ${ }^{(5)}$.

Dessa forma, o marco conceitual do Pensamento Complexo embasa a compreensão do objeto de estudo, que possui dupla face: a compreensão do processo de ensino e do fenômeno da Aids na contemporaneidade. Para isso, Morin auxilia a compreender a aids na sua condição pluridimensional, desconsiderando consequências redutoras e unidimensionais. Favorece a compreensão do processo de ensino como sistema comunicacional aberto e relacional integrado com as demais instâncias do sistema de saúde.

A coleta de dados foi realizada de janeiro a julho de 2010, em sete Instituições de Ensino Superior do município de São Paulo. Para participar dessa pesquisa (critério de inclusão), os docentes das instituições escolhidas deveriam ter: formação em enfermagem e ministrar conteúdos sobre HIV/Aids. Dessa forma, participaram do estudo treze docentes graduados em Enfermagem que ministram conteúdos sobre HIV/Aids. Para a coleta de dados foi utilizada a técnica de Entrevista Individual em Profundidade( ${ }^{(6)}$.

Obteve-se autorização dos responsáveis pelas instituições de ensino. Na sequência, o parecer favorável do Comitê de Ética em Pesquisa com Seres Humanos (protocolo CEP/Coordenadoria dos Serviços de Saúde - Instituto de Infectologia Emílio Ribas, registrado sob o número 197/2008) abriu espaço para que os docentes, indicados pelos responsáveis das instituições de ensino, com base nos critérios de inclusão proposto por este estudo, fossem orientados sobre o Termo de Consentimento Livre e Esclarecido. Assim, foram também informados que seus nomes e das instituições de Ensino Superior nas quais lecionam, não seriam revelados na socialização dos dados da pesquisa. As entrevistas foram conduzidas por duas questões norteadoras: 1. Como você compreende sua prática pedagógica em HIV/Aids? 2. Como você viabiliza o processo de ensino-aprendizagem em HIV/Aids na Graduação em Enfermagem?

Os dados empíricos foram trabalhados por meio da Técnica de Análise de Conteúdo ${ }^{(7)}$ em três momentos: pré-análise, exploração do material e tratamento dos resultados (inferência e interpretação). As etapas adotadas para construção consistente das categorias foram: $1^{\circ}$ - Após a transcrição na íntegra das entrevistas gravadas, realizou-se uma leitura dos textos a partir de uma atenção flutuante; $2^{\circ}$ - Por meio de nova releitura, foram grifadas palavras e frases dos textos originais, identificando-se convergências e divergências em cada entrevista; $3^{\circ}$ - Após serem identificadas as convergências e divergências, palavras e frases grifadas foram recortadas dos textos originais; $4^{\circ}$ - Após o recorte das palavras e frases, buscouse identificar convergências e divergências em cada entrevista e entre as entrevistas, para a elaboração das categorias; $5^{\circ}$ - Após a construção das categorias, procedeu-se a discussão dos dados. Relembramos que os procedimentos seguidos para a análise dos dados coletados por meio das técnicas de Entrevista Individual em Profundidade foram realizados com base no marco conceitual do Pensamento Complexo e dos objetivos propostos.

\section{RESULTADOS}

A partir da análise dos dados acerca da percepção dos treze docentes graduados em Enfermagem sobre sua prática pedagógica em HIV/Aids, emergiram quatro categoria.

\section{O processo ensino-aprendizagem em HIV/Aids com base no modelo biomédico}

Cada tema abordado sobre HIV/Aids está dentro de uma disciplina e muitas vezes, os temas em comum entre uma disciplina e outra, não são religados e não valorizados em relação ao contexto e ao sentido. Essa dificuldade em interligar os saberes é percebida por alguns docentes, como nos depoimentos a seguir, que têm a consciência da forte presença do modelo biomédico no ambiente acadêmico, como um grande auxiliador na promoção de saberes estanques. 
No caso de um portador de HIV, o aluno aprende que no hospital ele terá certo tipo de atendimento [...] diferente da Unidade Básica de Saúde, que foca na epidemiologia, que foca na prevenção [...]. As complicações vão para o hospital [...] É o modelo biomédico. (Professor 10)

[...] as pessoas não quererem sair de suas cátedras, não querem sair de seus castelos [...]. Cada um fica em seu castelo de conhecimentos e talvez, não abordamostodas as dimensões da aids. (Professor 3)

Esse modelo afeta a prática dos enfermeiros que se centram, quase que exclusivamente, nas necessidades físicas dos doentes. Dessa forma, a Enfermagem também age de maneira unidimensional, valorizando mais os aspectos técnicos e biológicos.

A seguir, percebe-se valorização dos conteúdos com enfoque no aspecto biológico:

[...] o aluno tem que saber sobre doenças oportunistas [...]. O aluno é levado para uma enfermaria especializada em infectologia, onde tem aids [...]. Lá eles veem sendo administrados antirretrovirais, eles discutem exame de imagem... vêoque épneumocistose na prática [...] (Professor 4)

Abordo a questão da aids em relação aos aspectos epidemiológicos, os sinais e sintomas, o tratamento, complicações da doença. Não trabalhamos os aspectos antropológicos e sociais da questão da aids [...]. (Professor 3)

A valorização dos conteúdos com enfoque nos aspectos psicossociais deveria ser tão fundamental quanto à valorização dos conteúdos biológicos. Há que se atentar para o desenvolvimento de um processo de ensino que valorize também os aspectos psicossociais do cuidado ao outro, de maneira a não fragmentar a condição humana.

\section{A participação ética dos acadêmicos na prestação de serviço à comunidade em relação ao HIV/ Aids}

Nessa categoria pode-se perceber, nos discursos dos docentes, há demonstração da importância da temática HIV/Aids na educação, como forma de participação direta dos acadêmicos na prestação de serviço à comunidade, no que tange à temática do HIV/Aids, uma vez que é nítida a preocupação desses docentes pensarem no processo que favoreça a saúde do coletivo:

O objetivo é mostrar para o aluno seu papel dentro dessa situação que é bastante abrangente [...] o papel deles nessa epidemia [...]. (Professor 1)

Nós enfermeiros e professores, temos a responsabilidade de orientar a população, mostrar para outras pessoas, inclusive pacientes com HIV/Aids, o direito que eles têm [...]. Sempre digo isso aos meus alunos. (Professor 9)

A visão crítica do docente, como balizadora de um ensino cidadão em HIV/Aids, deve aterse também a questão ética. A epidemia de aids trouxe à tona questões éticas imprescindíveis, desnudando uma variedade de desafios legais. Dessa forma, nos trechos dos discursos a seguir, percebe-se por parte dos docentes que há preocupação em trabalhar com os alunos à ética do cuidado ao indivíduo com HIV/Aids, discutindo os direitos humanos:

Eu acredito que seja muito mais do que você educar tecnicamente, mas promover cidadania com ética [...]. (Professor 13)

[...] o que a gente tem discutido muito, é a questão do direito. Não se o paciente é homossexual, se ele tem práticas assim ou assado [...] mas, a questão do direito humano, ele enquanto pessoa, enquanto cidadão [...]. (Professor 2)

A visão crítica do docente como balizadora de um ensino cidadão em HIV/Aids, comporta a educação voltada para a formação complexa e, portanto, solidária do sujeito que cuidará da pessoa com HIV/Aids.

\section{A curiosidade e a criatividade no processo ensino- aprendizagem em relação à temática HIV/Aids}

Reconhecer a importância da curiosidade e da criatividade no processo de ensino é fundamental para a construção do conhecimento e consequentemente, para a redução dos problemas 
da atualidade. Percebe-se, portanto, que o discurso a seguir demonstra que o docente reconhece a importância de instigar a curiosidade do aluno, para que o processo de ensino seja significativo. Em virtude disso, o aluno constrói o conhecimento em relação ao indivíduo com HIV/Aids de maneira personalizada, viva, atuante e criativa :

[...] uma das dificuldades maiores do paciente de HIV é em relação aos soro discordantes, que é uma situação que apareceu no estágio. A mulher era negativa e o marido positivo [...] ela queria engravidar [...] e para a aluna foi uma surpresa [...] e isso instigou a aluna a pesquisar [...]. Então, eu acho que são essas possibilidades de aprendizado [...]. (Professor 2)

A ideia da produção, como por exemplo, o estímulo à pesquisa, possibilita que o sujeito não só solucione criativamente uma dificuldade já dada, mas também que encontre um problema onde talvez outras pessoas não o vejam, o que constitui uma importante expressão de seu potencial de curiosidade e de criação :

Muitos alunos gostam da área de HIV/Aids e, a grande maioria das pesquisas produzidas por eles são sobre $o$ assunto [...]. (Professor 6)

Eu acho que você tem que instigar o aluno, estimular o aluno em relação a sua parte reflexiva em pesquisa [...]. (Professor 5)

Além das pesquisas, uma forma de estimular a curiosidade e a criatividade do aluno é fazer com que o próprio docente lance mão de sua criatividade, no processo de ensino em HIV/Aids. No trecho do próximo discurso, um dos docentes valendo-se de sua criatividade, propõe uma dinâmica, que ajuda os alunos a identificarem seus preconceitos e consequentemente, a lidarem de maneira significativa com eles. Assim, temos:

[...] eu uso dinâmica de grupo com os alunos. Separo a classe em dois grupos. Um constrói um homem e o outro uma mulher, e um deles tem HIV, e se isso conta em uma relação [...]. O meu papel é desconstruir o preconceito [...]. (Professor 12)

\section{Compreensão do humano com HIV/Aids como um ser complexo}

Nessa categoria, nota-se nas falas a seguir a preocupação das docentes em ensinar os alunos a olharem para a pessoa com HIV/Aids de maneira a compreender a condição humana, que vai além da doença em si e da maneira como o indivíduo contraiu o HIV:

Eu acho importante que eles conheçam pessoas com HIV [...] que reconheçam que essas pessoas não são diferentes da gente [...]. (Professor 2)

É necessário que a gente enxergue além da doença. Que o paciente é uma pessoa que precisa de cuidados, que precisa ser ouvida. (Professor 8)

Os discursos mostram a preocupação dos docentes em ensinar os alunos a não fecharem sua compreensão, reduzindo a pessoa com HIV/ Aids a "um bom ou mau comportamento" ou "culpar" sua condição por descuido. Ao contrário, atenta-os para o sofrimento dessas pessoas em relação ao "preconceito e ao estigma":

Eu acho importante que os alunos se atentem. Primeiro não culpar a pessoa que está com HIV, mas tentar entender quais são os processos que levaram essas pessoas a adquirirem o HIV [...]. (Professor 2)

Outra coisa é fazer com que o aluno participe de discussões em relação ao preconceito [...]. É descontruir a ideia de que o individuo com Aids teve um mau comportamento, que ele não teve uma conduta boa em sua vida e por isso adquiriu a doença. Eu tento desconstruir essa ideia. (Professor 7)

O próximo trecho reflete a importância da compreensão do humano com HIV/Aids como um ser complexo:

$O$ aluno precisa conhecer o paciente, a história de vida dele [...]. O aluno que vai para estágio não tem que conhecer apenas o prontuário, a fisiopatologia, as doenças oportunistas, os 
exames. Tem que fazer um histórico da vida do paciente, entender o processo da saúde/doença dele [...]. (Professor 11)

Os discursos dos docentes nessa quarta e última categoria nos conduziram a possibilidade de um processo de ensino focado na complexidade humana.

\section{DISCUSSÃO}

O objetivo deste estudo foi investigar a percepção dos docentes de Enfermagem sobre a sua prática pedagógica em HIV/Aids. Desta forma, é importante considerar que os docentes entrevistados têm compreensão aprofundada sobre o processo de ensino relacionado ao tema HIV/Aids, mas também percebem, como em outro estudo ${ }^{(4)}$, limites quanto à forte inserção do modelo cartesiano/biologicista no processo de ensino de Enfermagem.

Esse paradoxo permanente entre o fazer biomédico dos docentes e um projeto de idealização mais preocupado com as dimensões biopsicossociais no processo de ensino em HIV/ Aids reflete uma preocupação essencial na reforma do Pensamento proposta pela Teoria da Complexidade: o princípio dialógico. O Pensamento Moriniano traz a ideia da dialogia como aquela que permite a convivência de noções contraditórias numa mesma realidade, que não se sintetizam em uma nova percepção, mas sim em revelar o pensamento da realidade como complexo e processual ${ }^{(5)}$.

Dessa forma, os docentes aqui investigados são porta vozes dessa dialogia irresolúvel que permite que a ação dos docentes aconteça dentro do movimento da realidade, mesmo revelada em paradoxos como esse. Essa é a riqueza da vida e ação humana, pois permitem ao humano rever-se e a sua atividade no mundo, instaurando mudanças práticas e ideológicas, por exemplo, no cenário educacional. A construção do conhecimento em relação à temática HIV/ Aids, com vistas para o Pensamento Complexo requer que aprendamos a contextualizar, religar, globalizar e multidimensionalizar não só as informações, como também, o conhecimento ${ }^{(5)}$, principalmente porque a epidemia do HIV/Aids apresenta uma natureza mutável e dinâmica.
Os docentes percebem que o modelo biomédico tende a dividir o objeto de estudo ou as dificuldades surgidas em tantas parcelas quantas necessárias para resolvê-las, o que provoca a divisão do conhecimento em áreas cada vez mais especializadas ${ }^{(8)}$. Percebem também, que a doença é reduzida a uma avaria mecânica e o indivíduo doente perde suas marcas psicossociais, passando a ser um objeto cientifico, no qual os seus aspectos emocionais, crenças e valores são deixados de lado(4). Entretanto, sabe-se que a restrição ao modelo biomédico na formação de futuros enfermeiros, é de certa forma, comprometer a relação profissional e a

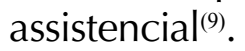

Quanto a participação ética dos acadêmicos na prestação de serviço à comunidade, o docente no processo de ensino em HIV/ Aids delineado pelo Programa Nacional de Doenças Sexualmente Transmissíveis e aids, deve apresentar um posicionamento ético em defesa da vida, da promoção da cidadania, da autonomia, da emancipação da pessoa humana, do respeito aos saberes, da busca de condições de vida mais dignas e igualitárias entre as pessoas ${ }^{(10)}$.

A participação direta dos acadêmicos na prestação de serviços à comunidade por meio do processo de ensino em HIV/Aids, possivelmente é o melhor exercício de cidadania experimentado pelos alunos. Pode ser de fato, o maior ganho proporcionado pelo trabalho cooperativo na busca da construção de vínculos mais sólidos, como parte de um novo compromisso ético firmado entre a universidade e a comunidade ${ }^{(8)}$. Dessa forma, o docente de Enfermagem ao trabalhar com o aluno o cuidado ao outro, passa a discutir a noção de ética e respeito ao próximo, essencial para a construção da cidadania $^{(5)}$. Portanto, diante da significação da ética, o docente deve também, dispor de um caráter humanista em relação aos alunos, sendo competente não só do ponto de vista técnico, mas acima de tudo humano, compreensivo e orientador, para mostrar-se como exemplo a ser seguido pelos alunos ${ }^{(9)}$.

Outro ponto fundamental refere-se à curiosidade e a criatividade. O processo de ensino que não usa das expressões criativas, geralmente, exclui a curiosidade, o entusiasmo, a descoberta, esvaziando de sentido esse processo $^{(11)}$. Tanto a curiosidade, quanto a 
criatividade são desenvolvidas quando o processo de ensino deixa de ser reprodutivo, passando a ser produtivo ${ }^{(11)}$. O ser humano quando deixa de estar submetido às ordens, mitos e crenças impostas, torna-se um sujeito questionador, porque se apresenta com o espírito liberto ${ }^{(12)}$. Isso se dá pelos processos de relação, por meio do diálogo, da reflexão e da contradição, elementos essenciais para implicar o sujeito no processo de ensino ${ }^{(12)}$.

O processo de ensino em relação à temática do HIV/Aids necessita da utilização de metodologias diversas, nas quais a curiosidade e a criatividade, tanto do docente para conduzir, quanto do aluno para participar, devem ser estimuladas, numa aproximação com o princípio moriniano da recursividade( ${ }^{(5)}$. Dessa forma, a valorização deste princípio no processo de ensino pode proporcionar enfoques inovadores na educação $0^{(13)}$ para ajudar a reduzir, por exemplo, o estigma e o preconceito em relação às pessoas com HIV/ Aids.

Em relação à compreensão do humano com HIV/Aids como um ser complexo, é necessário dizer que há duas formas de compreensão. A primeira, podemos chamar de compreensão intelectual ou objetiva, que passa pela inteligibilidade e pela explicação. A segunda é chamada de compreensão humana intersubjetiva, que vai além do conceito da primeira, pois percebe o outro não só de maneira objetiva, mas como uma pessoa com a qual nos identificamos e que se identifica conosco, numa relação de aproximação com o princípio moriniano da dialogia ${ }^{(12)}$.

A compreensão do outro engloba a compreensão objetiva, e também, comporta um elemento subjetivo indispensável, que consiste em não reduzir o outro a somente um dos seus traços, dos seus atos, mas tende a tomar em conjunto às diversas dimensões ou diversos aspectos da pessoa ${ }^{(5)}$. Os fatores que favorecem a compreensão são: a consciência da complexidade humana, a introspecção, a abertura subjetiva em relação ao outro, a interiorização da tolerância ${ }^{(12)}$.

No processo de ensino em Enfermagem sempre houve preocupação em prestar uma assistência de cuidados específicos e individualizados, de maneira a enxergar o indivíduo como um ser em sua totalidade. Dessa forma, há a necessidade de ver a pessoa com HIV/Aids em sua totalidade, mas também e, simultaneamente, na sua individualidade o que nos aproxima do princípio moriniano hologramático ${ }^{(12)}$. Como aquele que evidencia na compreensão de um sistema complexo, que a parte está sempre no todo, mas também o todo reverbera em sua parte, superando a visão cartesiana e estruturalista, que resume uma organização como soma de suas partes, cindidas e individualizadas ${ }^{(13)}$.

A construção da solidariedade é fundamental para o enfrentamento da epidemia de HIV/ Aids, devendo ser parte consciente das atitudes cotidianas dos futuros enfermeiros e da população em geral em respeito ao sujeito com HIV/Aids.

\section{CONSIDERAÇÕES FINAIS}

Inicialmente, é importante resgatar que a mola propulsora para a realização do presente estudo foi a necessidade de investigação a respeito da percepção dos docentes graduados em Enfermagem sobre sua prática pedagógica em HIV/Aids.

Percebe-se que a dimensão mais focada pelos docentes em relação ao processo de ensino em HIV/Aids foi a dimensão biológica. Entretanto, não se pode esquecer que a priorização da dimensão biológica, está significativamente relacionada ao fato da Enfermagem se constituir dentro do modelo biomédico, fruto do paradigma cartesiano, que valoriza esse aspecto. Entretanto, nota-se que os docentes têm clareza que o modelo biomédico limita a forma de enxergar o ser humano e reduz o processo de ensino em HIV/Aids em relação ao cuidado a ser ofertado.

$\mathrm{Na}$ prática pedagógica do processo de ensino em HIV/Aids elucidou-se a importância de estimular a criatividade e a curiosidade, que consiste no investimento de uma atividade pensante e que favorece o exercício de uma nova visão de mundo, porque tornam os sujeitos questionadores. Explicitou-se a valorização das pesquisas científicas e de estratégias de ensino como as dinâmicas de grupo e atividades com foco para o exercício da empatia, da projeção e da identificação com a pessoa com HIV/Aids no sentido de desconstruir o preconceito e o estigma.

Pode-se perceber que o processo de ensino em relação à temática HIV/Aids mostra-se em construção dialógica, permeado de contradições complementares entre a condição humana plural e o tecnicismo; a interligação de saberes e a fragmentação; o processo criativo e a repetição 
técnica. Portanto, esse estudo nos mostra que a semente da complexidade foi plantada no terreno fértil do processo de ensino em HIV/ Aids dos Cursos de Graduação em Enfermagem estudados. Essa semente vem se desenvolvendo e crescendo lentamente, o que nos faz vislumbrar a possibilidade de um processo de ensino em HIV/Aids pautado na condição humana, na solidariedade e na interligação do saber.

Temos clareza que este tema exige reflexão e não se esgota com esse trabalho. Dessa forma, seria interessante buscarmos estudar a percepção do aluno quanto a essa temática, no sentido de conhecermos o que de fato tem sido significante em seu aprendizado, com a finalidade de aprofundar os resultados apresentados nesta pesquisa.

Por fim, acreditamos que os resultados dessa pesquisa não são generalizáveis. A realidade dos campos de estudo em questão são singulares, apresentando características próprias no processo de ensino sobre a temática do HIV/Aids, sendo, portanto, uma limitação do estudo.

\section{REFERÊNCIAS}

1. Dantas GE, Fonseca PN, Brito FEB, Pontes AM, Pontes DHL. Percepção das pessoas vivendo com hiv/aids frente ao tratamento antirretroviral. Rev. Psicol. 2012;6 (17):48-64.

2. Morita I, Almeida MAS, Patricio KP, Ribeiro FAH. Origem do conhecimento sobre HIV/Aids: entre o pessoal e o acadêmico. Rev. bras. educ. med. 2012;36(2):197-203.

3. Borges MJL, Sampaio AS, Gurgel IGD. Trabalho em equipe e interdisciplinaridade: desafios para a efetivação da integralidade na assistência ambulatorial às pessoas vivendo com HIV/Aids em Pernambuco. Ciênc. saúde colet. 2012;17(1):147-56.

4. Camillo SO, Maiorino FT. A importância da escuta no cuidado de enfermagem. Cogitare enferm. 2012;17(3):549-55.

5. Morin E. Os sete saberes necessários a educação do futuro. São Paulo: Cortez; 2011.

6. Duarte J, Barros A. Métodos e Técnicas de Pesquisa em Comunicação. São Paulo: Atlas; 2010.

7. Bardin L. Análise de Conteúdo. São Paulo: Edições 70; 2011.

8. Camillo SO, Maiorino FL, Chaves LC. O ensino de enfermagem sobre HIV/Aids sob a ótica da cidadania.
Rev. Gaúcha Enferm. 2013;34(3):117-23.

9. Santos SSC, Hammerschmidt KSA. A complexidade e a religação de saberes interdisciplinares: contribuição do pensamento de Edgar Morin. Rev. bras. enferm. 2012;65(4):561-5.

10. Kawagoe J, Chaves LC, Fonseca FLA, Filipini R, Blake MDT, Camillo SO. As dificuldades de adaptação do convívio social de pacientes portadores de HIV/AIDS. Rev. bras. crescimento desenvolv. hum. 2012;22(1):3-97.

11. Wechsler SM, Nakano TC. Criatividade no Ensino Superior: uma perspectiva internacional. São Paulo: Vetor Editora; 2011.

12. Morin E. Educação e Complexidade- Os sete Saberes e Outros Ensaios.São Paulo: Cortez; 2013.

13. Morin E. O Métdo 4 - As Ideias. Porto Alegre: Sulina; 2011. 